\title{
Calcium-Dependent Inactivation of a Potassium Current in the Aplysia Neuron R15
}

\author{
Richard H. Kramer and Irwin B. Levitan \\ Graduate Department of Biochemistry, Brandeis University, Waltham, Massachusetts 02254
}

\begin{abstract}
The endogenously bursting pacemaker neuron R15 of Aplysia exhibits an inwardly rectifying $K^{+}$current $\left(I_{R}\right)$ that was shown previously to be enhanced by various neurotransmitters via the intracellular second messenger, cyclic AMP (Drummond et al., 1980; Benson and Levitan, 1983; Levitan et al., 1987). Here we present evidence that $\mathrm{Ca}^{2+}$ influx, either caused by spontaneous bursting activity or elicited by depolarizing voltage-clamp pulses, causes a large, long-lasting inactivation of $I_{R}$. The ionic current inactivated by bursts is identified as $I_{R}$ by several criteria: it activates steeply at membrane potentials more negative than the $\mathrm{K}^{+}$equilibrium potential, has very fast kinetics, is reduced by lowering external $\mathrm{K}^{+}$from 10 to $2 \mathrm{~mm}$, and is blocked by adding $1 \mathrm{~mm}$ $\mathrm{Ba}^{2+}, 10 \mathrm{mM} \mathrm{Cs}$, or $5 \mathrm{mM} \mathrm{Rb}{ }^{+}$to the bathing medium. The peak inactivation of $I_{F}$ is delayed following a single burst of spikes in R15, such that $I_{R}$ decreases maximally by about $20 \%$ after $60-90 \mathrm{sec}$, and then recovers gradually over more than $10 \mathrm{~min}$. The inactivation caused by many bursts of spikes can reduce $I_{R}$ to less than $50 \%$ of its initial amplitude. The delay in onset and slow time course of recovery from inactivation of $I_{R}$ suggest that a complex biochemical mechanism underlies the effect of $\mathrm{Ca}^{2+}$ on $\mathrm{I}_{\mathrm{A}}$.

The effect of depolarization on $I_{R}$ is due specifically to the influx and intracellular accumulation of $\mathrm{Ca}^{2+}$. Depolarizing voltage-clamp pulses are maximally effective at reducing $I_{\mathrm{R}}$ when they elicit a large influx of $\mathrm{Ca}^{2+}$, while pulses approaching the $\mathrm{Ca}^{2+}$ equilibrium potential have little effect. The effect of depolarizing pulses on $I_{R}$ is blocked by removing $\mathrm{Ca}^{2+}$ from the bathing medium and adding $3 \mathrm{~mm} \mathrm{Mn}{ }^{2+}$ to block $\mathrm{Ca}^{2+}$ channels, or by intracellular injection of the $\mathrm{Ca}^{2+}$ chelator EGTA. The results indicate that changes in intracellular $\mathrm{Ca}^{2+}$ occurring during normal bursting activity in $\mathrm{R15}$ cause a profound inactivation of $I_{R}$. Hence, $I_{R}$ is modulated in opposite directions by 2 intracellular messengers in the same neuron; it is enhanced by intracellular CAMP and it is inactivated by intracellular $\mathrm{Ca}^{2+}$.
\end{abstract}

Calcium ions regulate a diverse assortment of ionic currents in a wide variety of cells. Intracellular $\mathrm{Ca}^{2+}$ is known to activate $\mathrm{K}^{+}$(for review, see Meech, 1978; Latorre et al., 1984), $\mathrm{Cl}^{-}$(Barish, 1983), and nonselective cation currents (Colquhoun et al., 1981; Maruyama and Peterson, 1982; Yellen, 1982; Kramer

\footnotetext{
Received July 16, 1987; revised Oct. 5, 1987; accepted Oct. 8, 1987.

We thank George Augustine and John Lisman for helpful comments on the manuscript This work was supported by NIH Grant NS17910 to I.B.L.

Correspondence should be addressed to Dr. Kramer at the above address.

Copyright (c) 1988 Society for Neuroscience $0270-6474 / 88 / 051796-08 \$ 02.00 / 0$
}

and Zucker, 1985a). In addition, internal $\mathrm{Ca}^{2+}$ causes the inactivation of $\mathrm{Ca}^{2+}$ currents (for review, see Eckert and Chad, 1984). This diverse assortment of $\mathrm{Ca}^{2+}$-regulated currents enables $\mathrm{Ca}^{2+}$ to play a central role in controlling the electrophysiology of cells.

$\mathrm{Ca}^{7+}$-regulated ionic currents have been studied in great detail in Aplysia bursting pacemaker neurons. Regulation of ionic currents by changes in intracellular $\mathrm{Ca}^{2+}$ is essential for generating the oscillation of membrane potential that drives bursting pacemaker activity (Gorman et al., 1982). There are $3 \mathrm{Ca}^{2+}$-regulated currents previously identified in these cells: (1) $\mathrm{Ca}^{2+}$-activated $\mathrm{K}^{+}$current ( $\left.\mathrm{I}_{\mathrm{K}(\mathrm{Ca})}\right)$ (Gorman and Hermann, 1979; Meech, 1979), (2) $\mathrm{Ca}^{2}$-activated nonselective cation current $\left(\mathbf{I}_{\mathrm{Cat}(\mathrm{Ca})}\right)$ (Kramer and Zucker, 1985a), and (3) voltage-gated $\mathrm{Ca}^{2+}$ current $\left(\mathrm{I}_{\mathrm{Ca}}\right)$, which is inactivated by $\mathrm{Ca}^{2+}$ (Eckert and Tillotson, 1981; Kramer and Zucker, 1985b). The $\mathrm{Ca}^{2+}$ that enters the neuron during a burst of action potentials accumulates near the membrane and acts quickly to activate or inactivate these 3 ionic currents. Following the burst, the magnitude of each of these currents returns to its initial level with distinct kinetics as the elevated intracellular $\mathrm{Ca}^{2+}$ concentration returns to normal. Hence the $\mathrm{Ca}^{2+}$-dependent regulation of these 3 currents determines the timing of bursting pacemaker activity.

The subject of this paper is the identification of an additional effect of intracellular $\mathrm{Ca}^{2+}$ on an ionic current in the Aplysia neuron R15. Neuron R15 exhibits an inwardly ("anomalously") rectifying $\mathrm{K}^{+}$current $\left(\mathrm{I}_{\mathrm{R}}\right)$ that activates with hyperpolarization (Benson and Levitan, 1983). Normally, the membrane potential of R 15 does not become sufficiently hyperpolarized to activate a large amount of $I_{R}$. However, the neurotransmitter serotonin (5-HT) (Benson and Levitan, 1983; Lotshaw et al., 1986) and the neuropeptide egg-laying hormone (ELH) (Levitan et al., 1987) cause a large enhancement of $I_{R}$ in cell $R 15$. There is convincing evidence that the effects of these transmitters are mediated by an increase in the level of cAMP in R15 (Drummond et al., 1980; Levitan et al., 1987). Activation of adenylate cyclase, inhibition of phosphodiesterase, and application of membranepermeable cAMP analogs all lead to an increase in $I_{R}$ (Levitan and Adams, 1981). In addition, application of both 5-HT (Levitan and Drummond, 1980) and ELH (Levitan et al., 1987) causes an increase in the content of cAMP in single R15 cells. The enhancement of $I_{R}$ by cAMP results in an augmentation of the hyperpolarizing phase of bursting pacemaker activity.

In this paper we present evidence for a novel action of intracellular $\mathrm{Ca}^{2+}$ : The influx and intracellular accumulation of $\mathrm{Ca}^{2+}$ leads to the prolonged inactivation of the inwardly rectifying $K^{+}$current in neuron $R 15$. Hence $I_{R}$ is an ionic current that is modulated in opposite ways by 2 intracellular messengers, $\mathrm{Ca}^{2+}$ 
and cAMP. In the following paper (Kramer et al., 1988), the biochemical mechanism of the regulation of $I_{R}$ by intracellular $\mathrm{Ca}^{2+}$ is examined. A preliminary report of this work has appeared previously (Kramer and Levitan, 1986).

\section{Materials and Methods}

Aplysia californica (200-400 gm), obtained from Alacrity Marine Biologicals (Redondo Beach, $\mathrm{CA}$ ) and maintained at $16^{\circ} \mathrm{C}$, were used in all experiments. The abdominal ganglion was removed and pinned to a Sylgard base of a plastic chamber with a volume of $1 \mathrm{ml}$. The ganglion was desheathed, and R 15 was impaled with 2 intracellular microelectrodes (2-5 M $)$ ) filled with $0.5 \mathrm{M} \mathrm{K}_{2} \mathrm{SO}_{4}$ for conventional 2-electrode voltage clamping.

Ganglia were bathed in saline consisting of $420 \mathrm{~mm} \mathrm{NaCl}, 100 \mathrm{~mm}$ $\mathrm{MgCl}_{2}, 10 \mathrm{~mm} \mathrm{KCl}, 10 \mathrm{~mm} \mathrm{CaCl}$, and $10 \mathrm{~mm}$ NaHEPES (pH 7.5). This medium contains $50 \mathrm{~mm}$ more $\mathrm{MgCl}_{2}$ and $70 \mathrm{~mm}$ less $\mathrm{NaCl}$ than were used previously (i.e., Kramer and Zucker, 1985a) in order to minimize spontaneous synaptic inputs onto cell $R 15$. In addition, $0.5 \mathrm{~mm}$ hexamethonium (Sigma) was sometimes added to block spontaneous cholinergic inputs. The effect of $\mathrm{Ca}^{2+}$ influx on $I_{R}$ was essentially unaffected by the use of high $\mathrm{Mg}^{2+}$ or hexamethonium. Nominally $\mathrm{Ca}^{2+}$-free saline contained no added $\mathrm{CaCl}_{2}$ and $3 \mathrm{mM} \mathrm{MnCl}_{2}$. Low-K $\mathrm{K}^{+}$saline contained $2 \mathrm{~mm} \mathrm{KCl}$. Ganglia were continuously superfused with saline solutions $\left(21-23^{\circ} \mathrm{C}\right)$ at $2-3 \mathrm{ml} / \mathrm{min}$.

The 2-electrode voltage-clamp arrangement used was as described in Kramer and Zucker (1985a). Membrane current was measured with a virtual ground circuit. Signals were low-pass-filtered with an active filter with a corner frequency of $100 \mathrm{~Hz}$. EGTA was injected iontophoretically into cells through a third thin-wall glass microelectrode filled with 0.25 $M \mathrm{~K}$,EGTA. Ions were injected under voltage-clamp so that the current used for the injection did not cause a change in the membrane potential. Injections were accomplished with a constant-current iontophoresis unit (Model 160, W-P Instruments), while the current was monitored with an isolation amplificr circuit.

\section{Results}

Effect of bursting activity on membrane conductance

$\mathrm{Ca}^{2+}$ influx caused either by spontaneous bursting activity or controlled depolarization under voltage-clamp has effects on $\mathrm{I}_{\mathrm{K}(\mathrm{Ca})}, \mathrm{I}_{\mathrm{cat}(\mathrm{Ca})}$, and $\mathrm{I}_{\mathrm{Ca}}$ in Aplysia bursting neurons, as described previously (Gorman and Hermann, 1979; Eckert and Tillotson, 1981; Adams and Levitan, 1985; Kramer and Zucker, 1985a, b). In addition, $\mathrm{Ca}^{2+}$ influx regulates a distinct ionic current that activates upon hyperpolarization of the membrane potential in cell R15. Figure 1 shows the effect of bursting activity on membrane currents (top) elicited by applying $40 \mathrm{mV}$ hyperpolarizing voltage pulses (bottom) from a holding potential of $-90 \mathrm{mV}$. The cell had been held at $-90 \mathrm{mV}$ for more than $15 \mathrm{~min}$ to allow the membrane conductance to reach steady state. At the arrow in Figure $1 \mathrm{~A}$, the cell was released from voltage-clamp and allowed to fire a spontaneous burst of 12 action potentials. The cell was then voltage-clamped to $-90 \mathrm{mV}$ once again, and the hyperpolarizing pulses were resumed. After the burst of spikes there is a decrease in the inward current generated by the hyperpolarizing pulses; hence there is a decrease in the membrane conductance. The effect on the membrane conductance does not appear to be immediate, but develops gradually after termination of the burst, such that the membrane conductance is smallest $60-90 \mathrm{sec}$ after the burst. In Figure $1 A$, the steadystate membrane conductance decreased from $1 \mu \mathrm{S}$ before the burst to $0.75 \mu \mathrm{S} 90 \mathrm{sec}$ after the burst.

The effect of bursts on the membrane conductance is more dramatic if multiple bursts are allowed to occur. In Figure $1 B$ the cell was released from voltage-clamp, and a total of 45 spontaneous bursts occurred over a period of $400 \mathrm{sec}$. The result is a decrease in the membrane conductance from $1 \mu \mathrm{S}$ before the bursts to $0.38 \mu \mathrm{S}$ immediately after the bursts. It should be noted that, following this long period of bursting, there is no delay in the conductance decrease, but instead the conductance is minimal immediately after the series of bursts and rises steadily as the cell remains hyperpolarized under voltage-clamp. The lack of an apparent delay suggests that the process that regulates the membrane conductance reaches steady state during the long period of bursting activity.

The time course of the decrease in membrane conductance following 1, 3, or 10 bursts of spikes is shown in Figure 2. In each case the conductance was allowed to reach steady state by holding the cell at $-75 \mathrm{mV}$ for at least $25 \mathrm{~min}$ before the bursts were allowed to occur. The decrease in membrane conductance caused by bursting activity takes more than 10 min to recover fully after a single burst of spikes, and lasts even longer following 3 or 10 bursts. The fraction of the resting membrane conductance blocked by bursts increases with additional bursts, such that a single burst blocks $12-26 \%$ of the conductance $(n=9)$, while a train of 10 bursts blocks $36-50 \%(n=4)$ of the resting membrane conductance. The long time course of recovery and the additive effect of bursts on the membrane conductance suggest that the factor responsible for reducing the membrane conductance accumulates over many bursts. There is once again a delay of about $60-90 \mathrm{sec}$ between the end of the bursts and the maximal decrease of the membrane conductance. The fraction of the total conductance decrease that is delayed in onset diminishes as additional bursts are added such that, after 10 bursts, the membrane conductance $15 \mathrm{sec}$ after the bursts is nearly the same as that $90 \mathrm{scc}$ aftcr the bursts. This again suggests that the process responsible for decreasing the membrane conductance approaches steady state after repeated bursts of action potentials.

\section{Ionic basis of the conductance decrease}

Voltage-clamp studies of R 15 cells have shown that most of the ionic current at membranc potentials more hyperpolarized than $-75 \mathrm{mV}$ is due to $I_{R}$ (Benson and Levitan, 1983). In order to test whether $I_{R}$ is affected by bursting activity as is the current shown above, ionic substitution experiments and specific pharmacological blockers of $I_{R}$ were employed. The voltage-clamp pulse paradigm illustrated in Figure $3 A$ was used in these experiments. The cell was held at $-75 \mathrm{mV}$ and $200-400 \mathrm{msec}$ depolarizing and hyperpolarizing voltage pulses were applied in order to measure membrane currents and construct a steadystate current-voltage (I-V) curve. A train of five $200 \mathrm{msec}$ depolarizing pulses to $+20 \mathrm{mV}$ was applied to simulate a burst of action potentials.

The simulated burst has prolonged effects on 2 distinct ionic currents in R15. First, the simulated burst causes a long-lasting reduction (inactivation) of an inward current that appears upon hyperpolarization of the membrane potential negative to -75 $\mathrm{mV}$ (Fig. $3 B$ ). This current activates so rapidly (within $2 \mathrm{msec}$ ) after a voltage step that it appears without a delay after the decay of the capacitative current. Hence we could not distinguish the hyperpolarization-induced current from the instantaneous leakage conductance of the membrane unless pharmacological blockers were used (see below). The rapid kinetics characteristic of this current are typical of $I_{R}$ found in other systems (e.g., Hagiwara and Takahashi, 1974). R15 cells that were damaged during the course of an experiment exhibited a time-dependent component of the hyperpolarization-induced inward current, probably due to a slow hyperpolarization-gated $\mathrm{Cl}^{-}$current 


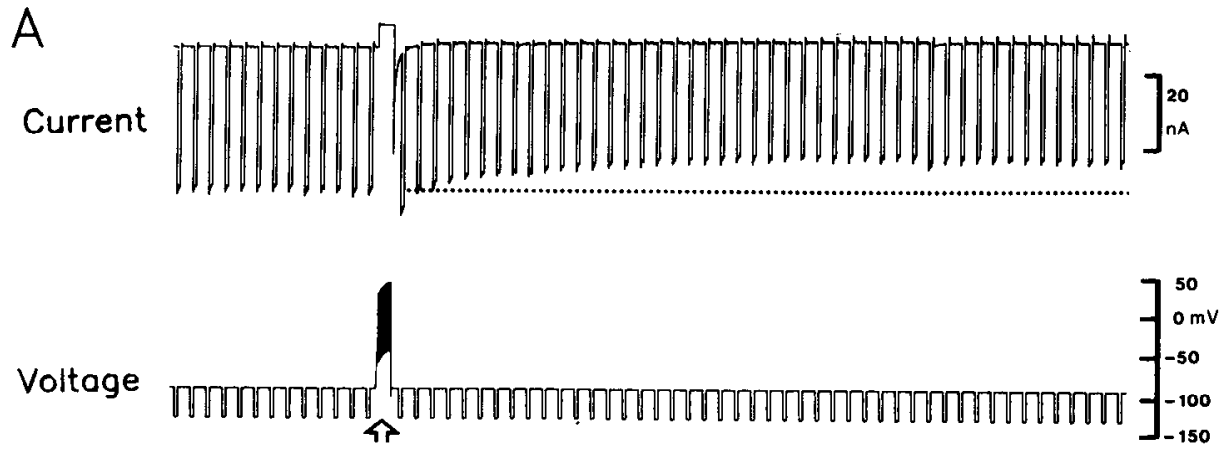

Figure 1. Effect of bursting activity on membrane conductance in cell R15. $A$, Membrane currents elicited by repeated $400 \mathrm{msec}$ hyperpolarizing voltage pulses from -90 to $-130 \mathrm{mV}$. At the arrow, the cell was released from clamp and fired a burst of spikes. Membrane current decreases in amplitude, with a delay, after the cell is once again voltage-clamped. $B$, Large decrease in the amplitude of membrane currents after multiple bursts of spikes. Note the lack of delay in onset of the effect. Voltage pulses are the same as in part $A$. Dotted lines in $A$ and $B$ denote the membrane current level before the burst(s)
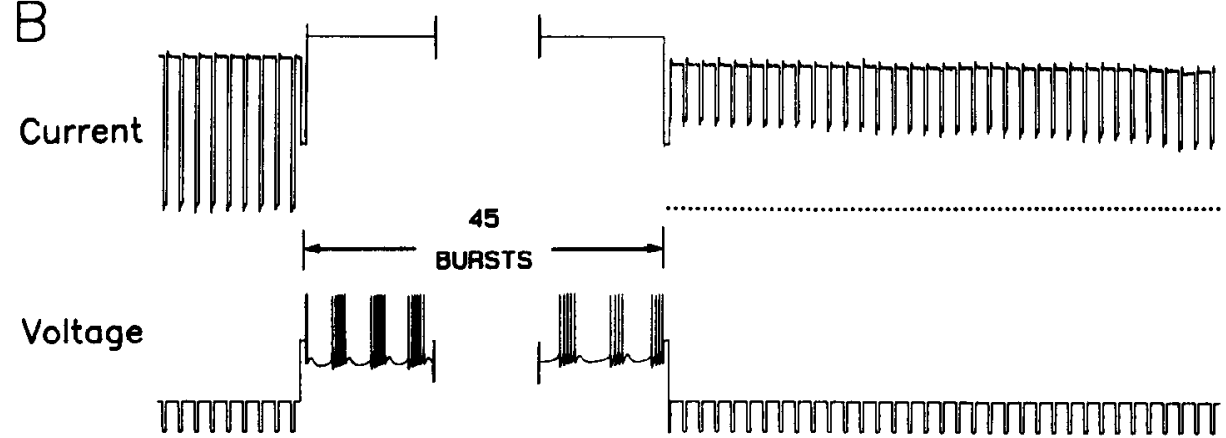

(Chesnoy-Marchais, 1983; Lotshaw et al., 1986). Cells that exhibited this current were not used in this study. The simulated burst also causes the reduction (inactivation) of a second voltage-gated inward current in R15. This current appears upon depolarization of the membrane potential positive to $-75 \mathrm{mV}$, and exhibits slow kinetics (Fig. 3C). This slow inward current has previously been identified as a subthreshold voltage-gated $\mathrm{Ca}^{2+}$ current (Eckert and Lux, 1976; Gorman et al., 1982; Kramer and Zucker, 1985b).

The 2 ionic currents partially inactivated by the simulated burst can be seen clearly in the I-V curve of Figure $4 A$. The simulated burst causes a decrease in the inward current and

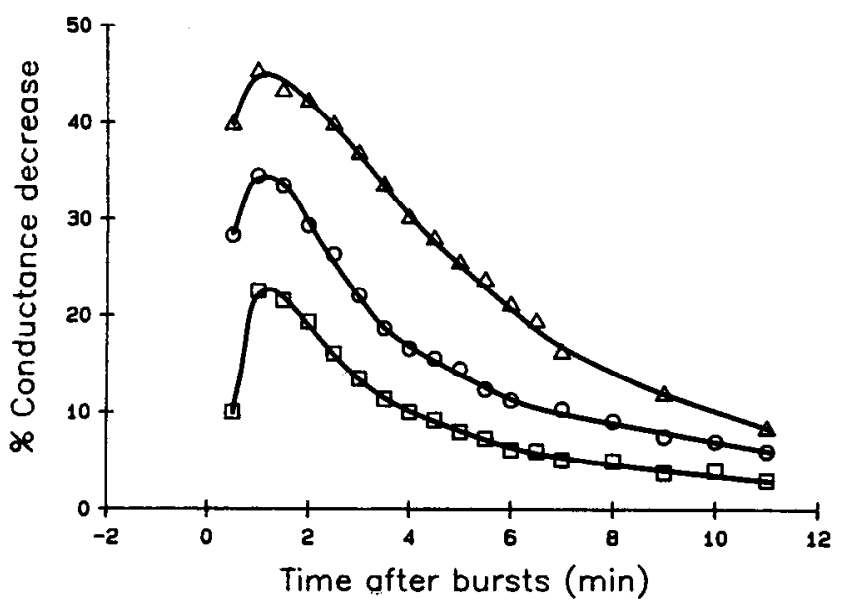

Figure 2. Time course of the conductance decrease following bursts of spikes in R15. The membrane conductance between -75 and -115 $\mathrm{mV}$ was measured at various times after 1 (squares), 3 (circles), or 10 (triangles) bursts of spikes. Percentage conductance decrease is the difference between the conductance after and before the bursts, divided by the conductance before the bursts. reduces the slope of the I-V curve at membrane potentials more negative than $-75 \mathrm{mV}$, as expected when $I_{R}$ is decreased by the burst. Application of 5-HT (Benson and Levitan, 1983) or ELH (Levitan et al., 1987) increases the slope of the I-V curve negative to $-75 \mathrm{mV}$ by increasing $\mathrm{I}_{\mathrm{R}}$. The $\mathrm{K}^{+}$equilibrium potential is near $-75 \mathrm{mV}$ in Aplysia neurons in normal saline (Coyer et al., 1983); hence a decrease in the $\mathrm{K}^{+}$conductance at membrane potentials more negative than $-75 \mathrm{mV}$ should result in an outward shift in current. It is therefore likely that the burst causes an inactivation of $I_{R}$. The burst also causes a decrease in a second inward current that activates with depolarization at membrane potentials positive to $-75 \mathrm{mV}$. Molluscan bursting neurons, including $\mathrm{R} 15$, are known to have a voltage-gated subthreshold $\mathrm{Ca}^{2+}$ current that activates between -75 and $-30 \mathrm{mV}$ (Eckert and Lux, 1976; Gorman et al., 1982; Kramer and Zucker, 1985b). The regenerative activation of this current underlies the depolarizing pacemaker wave that initiates bursts of spikes. The subthreshold $\mathrm{Ca}^{2+}$ current is known to be inactivated by $\mathrm{Ca}^{2+}$ influx that occurs during bursts (Kramer and Zucker, 1985b). Hence the decrease in the inward current at potentials positive to $-75 \mathrm{mV}$ probably represents $\mathrm{Ca}^{2+}$-dependent inactivation of the $\mathrm{Ca}^{2+}$ current (Eckert and Tillotson, 1981). The amplitudc of the $\mathrm{Ca}^{2+}$ current, the magnitude of its inactivation, and the time course of the recovery from inactivation were quite variable in different $\mathrm{R} 15$ cells. Hence, the inactivation of the $\mathrm{Ca}^{2+}$ current is not always apparent $90 \mathrm{sec}$ after the burst (e.g., Fig. $7 A)$.

If the current affected by the burst negative to $-75 \mathrm{mV}$ is due to $I_{R}$, then the effect of the burst on this region of the I-V curve should be diminished in the presence of agents that reduce or block $I_{R}$. In cell R15 (Benson and Levitan, 1983), as well as in other systems (Hagiwara and Takahashi, 1974; Sakmann and Trube, 1984), $I_{R}$ is greatly reduced by lowering the external $\mathrm{K}^{+}$ concentration. This is because the activation of $I_{R}$ is shifted as the $\mathrm{K}^{+}$equilibrium potential is shifted to more hyperpolarized 


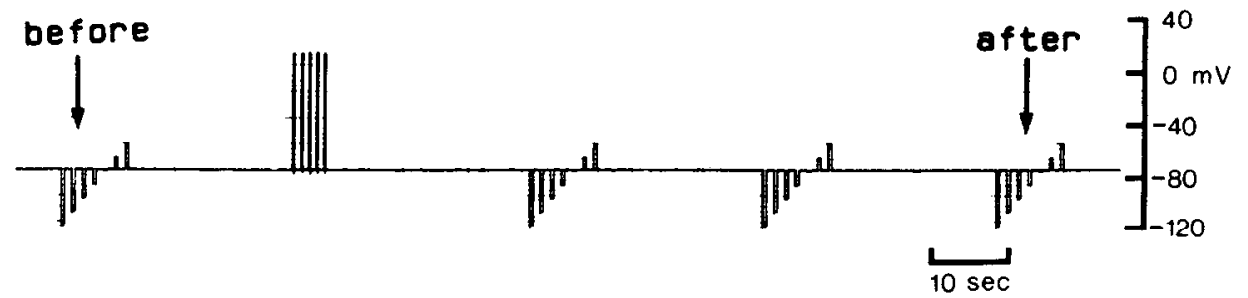

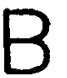

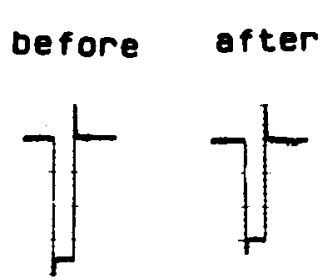

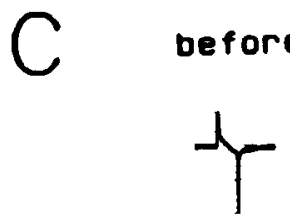

befor

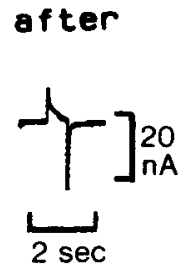

Figure 3. Effect of a simulated burst on ionic currents in R15. $A$, Paradigm for measuring steady-state I-V characteristics before and after a simulated burst of spikes. The cell was held at -75 $\mathrm{mV}$ under voltage-clamp and a series of $400 \mathrm{msec}$ pulses of $10 \mathrm{mV}$ increments (e.g., from -125 to $-55 \mathrm{mV}$ ) was applied at $30 \mathrm{sec}$ intervals in order to construct steady-state I-V curves. The simulated burst consisted of five 200 msec pulses to $+20 \mathrm{mV}$. Typically, the I-V curve obtained $15 \mathrm{sec}$ before the burst was compared to the I-V curve obtained $90 \mathrm{sec}$ after the burst. $B$, Currents resulting from $400 \mathrm{msec}$ hyperpolarizing pulses from -75 to -115 $\mathrm{mV} 15 \mathrm{sec}$ before and $90 \mathrm{sec}$ after the burst. $C$, Currents resulting from 400 msec depolarizing pulses from -75 to $-55 \mathrm{mV} 10 \mathrm{sec}$ before and $95 \mathrm{sec}$ after the burst. potentials, and because the conductance of $I_{R}$ channels is dependent on the external $\mathrm{K}^{+}$concentration. Figure $4 B$ shows the effect of low external $\mathrm{K}^{+}(2 \mathrm{mM})$ on the $\mathrm{I}-\mathrm{V}$ curve and on its modulation by a burst. The conductance decreased by the burst is shifted such that it now activates at membrane potentials negative to $-105 \mathrm{mV}$, in accord with the expected shift of the $\mathrm{K}^{+}$equilibrium potential to $-110 \mathrm{mV}$ in $2 \mathrm{mM} \mathrm{K}$. Furthermore, both the membrane conductance negative to $-105 \mathrm{mV}$ and the inactivation of the conductance are decreased in $2 \mathrm{~mm} \mathrm{~K}^{+}$. The inactivation of the $\mathrm{Ca}^{2+}$ conductance at depolarized potentials (more positive than $-75 \mathrm{mV}$ ) is still apparent in $2 \mathrm{~mm} \mathrm{~K} \mathrm{~K}^{+}$.

$I_{R}$ is blocked by low concentrations of various cations, including $\mathrm{Ba}^{21}, \mathrm{Cs}^{1}$, and $\mathrm{Rb}^{+}$in cell $\mathrm{R} 15$ (Benson and Levitan, 1983), and in other systems (Hagiwara et al., 1978; Standen and Stanfield, 1978, 1980). The effect of $\mathrm{Ba}^{2+}$ on the I-V curve, and on its modulation by a burst, is shown in Figure 5. In this R15 neuron the simulated burst resulted in a large long-lasting decrease in the slope of the $\mathrm{I}-\mathrm{V}$ curve negative to $-75 \mathrm{mV}$, while the effect on the inward $\mathrm{Ca}^{2+}$ current was small and recovered almost completely within $90 \mathrm{sec}$ (Fig. $5 A$ ). In the presence of 1 $\mathrm{mM} \mathrm{Ba}{ }^{2+}$, the inward current negative to $-75 \mathrm{mV}$ was greatly reduced, and the effect of the burst on this region of the I-V curve was almost completely blocked (Fig. 5B). In contrast, $\mathrm{Ba}^{2+}$ caused a $10 \%$ enhancement in the inward $\mathrm{Ca}^{2+}$ current and a small enhancement of $\mathrm{Ca}^{2+}$-dependent tail currents that occur after depolarizing voltage-clamp pulses (data not shown). In each of 4 experiments with $1 \mathrm{mM} \mathrm{Ba}{ }^{2+}$, the effect of the burst on the conductance negative to $-75 \mathrm{mV}$ was reduced by at least $85 \%$. In other experiments, using $10 \mathrm{mM} \mathrm{Cs}^{+}(n=2)$ or $5 \mathrm{~mm}$ $\mathrm{Rb}^{+}(n=2)$, the effect of the burst was also reduced each time by more than $85 \%$. Hence the conductance affected by the burst has the expected characteristics of $I_{R}$ : it activates very rapidly

A
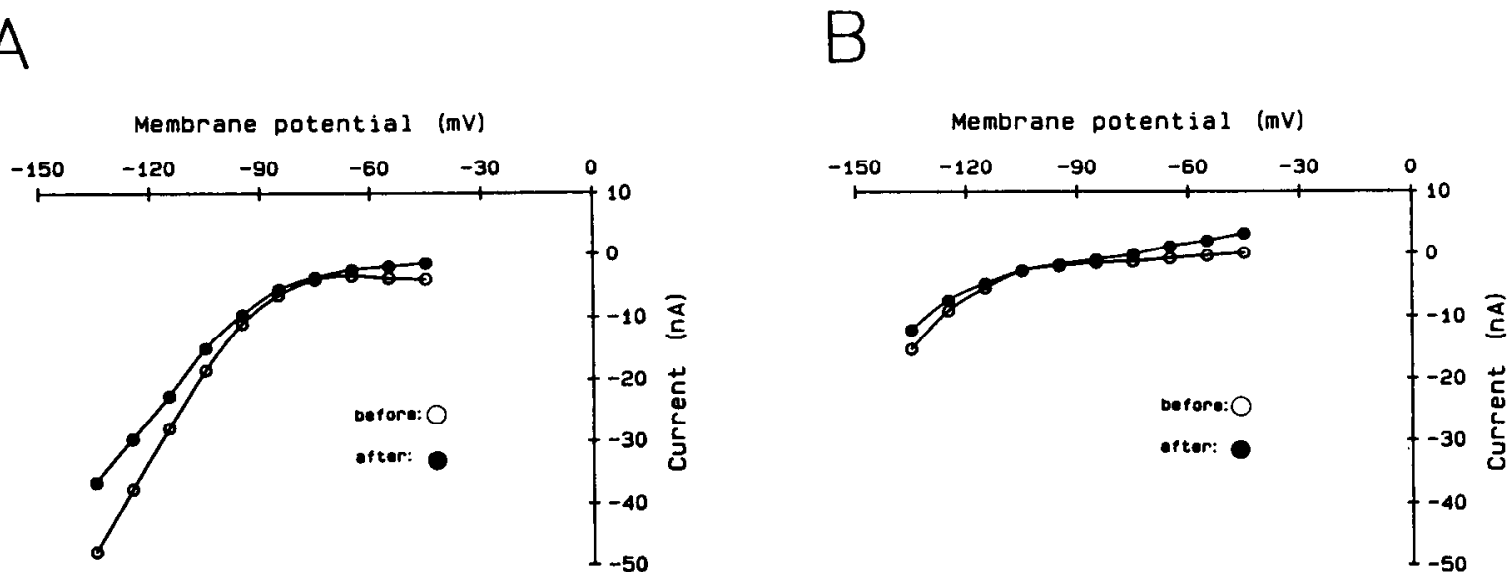

Figure 4. Effect of the simulated burst on the I-V curve of $\mathrm{R} 15$ in normal saline $(A)$ and in low-K $\mathrm{K}^{+}(2 \mathrm{~mm})$ saline $(B)$. In normal saline, 2 inward currents are decreased after the burst, one appearing negative to $-75 \mathrm{mV}$ and one appearing positive to $-75 \mathrm{mV}$. In low- $\mathrm{K}^{+}$saline, the conductance decrease in the hyperpolarized range is shifted to potentials more negative than $-110 \mathrm{mV}$, while the conductance decrease in the depolarized range (positive to $-75 \mathrm{mV}$ ) is not greatly affected. I-V curves were obtained as in Figure 3,15 sec before and 90 sec after the burst. In this and other figures, "steady-state" currents were measured at the end of each $400 \mathrm{msec}$ pulse and are plotted with respect to pulse potential. 

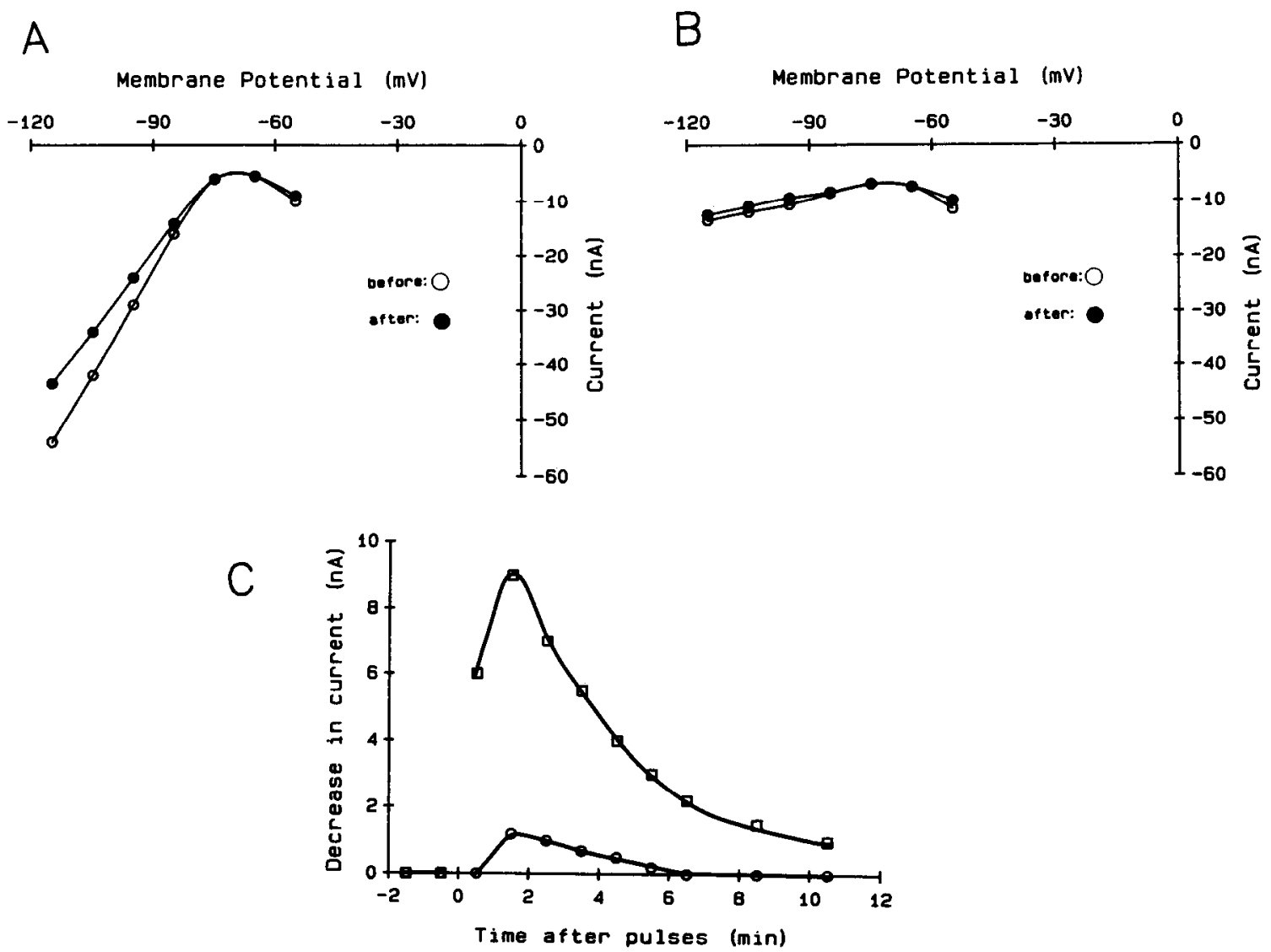

Figure 5. Effect of $\mathrm{Ba}^{2+}$ on the burst-induced changes in the I-V curve. $A$, Effect of the burst on the I-V curve in normal saline. B, Effect of the burst on the $\mathrm{I}-\mathrm{V}$ curve in saline containing $1 \mathrm{~mm} \mathrm{Ba}{ }^{2+}$. I-V curves were obtaincd $15 \mathrm{scc}$ beforc and 90 sce after the burst, as in Figure 3 . $C$, Time course of the effect of the simulated burst in normal saline (squares) and in saline containing $1 \mathrm{mM} \mathrm{Ba}^{2+}$ (circles). Note that $1 \mathrm{~mm} \mathrm{Ba}{ }^{2+}$ does not reveal any transient $(90 \mathrm{sec})$ conductance increase induced by the burst.

upon hyperpolarization at potentials more negative than the $\mathrm{K}^{+}$ equilibrium potential; it is diminished by low external $\mathrm{K}^{+}$; and it is blocked by low concentrations of specific blocking cations.

Once we learned the identity of the ionic current responsible for the long-lasting conductance decrease, we wondered about the cause of the apparent delay in its inactivation following a burst. The apparent delay may result from a slowly developing process that reduces $I_{R}$, or it may result from a large transient conductance increase that obscures the conductance decrease during the initial $90 \mathrm{sec}$ after a burst. We again used $\mathrm{Ba}^{2+}$ as a tool in distinguishing between these 2 possibilities. If a burst indeed elicits a $90 \mathrm{sec}$ conductance increase, then this should be revealed by adding $1 \mathrm{mM} \mathrm{Ba}{ }^{2+}$, which completely blocks $I_{R}$, but which we found to have little effect on other $\mathrm{Ca}^{2+}$-regulated currents at this low concentration. Figure $5 C$ shows the time course of the effect of the burst on $I_{R}$ in normal saline and in 1 $\mathrm{mM} \mathrm{Ba}{ }^{2+}$ saline. The time course of the effect of the simulated burst on $I_{R}$ is similar to the time course of the effect of a natural burst on $I_{R}$ (see Fig. 2). After addition of $\mathrm{Ba}^{2+}$, the effect of the simulated burst on the membrane conductance is greatly reduced at all times after the burst. There is no transient conductance increase revealed by the addition of $\mathrm{Ba}^{2+}$. Hence, the delay in the inactivation of $I_{R}$ after a burst seems to be authentic.

Inactivation of $I_{R}$ is $\mathrm{Ca}^{2+}$-dependent

Bursts of action potentials in cell R15 elicit a large influx of $\mathrm{Ca}^{2+}$
(Gorman and Thomas, 1978), which regulates various ionic currents, including inactivating the $\mathrm{Ca}^{2+}$ current (Eckert and Tillotson, 1981; Kramer and Zucker, 1985b). Therefore, it seemed likely that the long-lasting inactivation of $I_{R}$ caused by bursts also results from $\mathrm{Ca}^{2+}$ influx. The following experiments were designed to test this hypothesis.

In order to test whether $\mathrm{Ca}^{2+}$ influx is required for $I_{R}$ inactivation, the amplitude of the depolarizing pulses that comprise a simulated burst was varied. Depolarizing voltage-clamp pulses large enough to approach the $\mathrm{Ca}^{2+}$ equilibrium potential (estimated at about $+150 \mathrm{mV}$; Hagiwara and Byerly, 1981) should elicit little $\mathrm{Ca}^{2+}$ influx. Figure $6 \mathrm{~A}$ shows the effect of a burst of depolarizing pulses to either $+30 \mathrm{mV}$ or to $+100 \mathrm{mV}$ on $I_{R}$ elicited by repeated pulses from -70 to $-110 \mathrm{mV}$. The burst of pulses to $+30 \mathrm{mV}$ caused a considerable inactivation of $I_{R}$, while the burst to +100 caused no noticeable inactivation in this R15 cell. The graph of Figure $6 B$ shows the relationship between $I_{R}$ inactivation and pulse potential in a more representative $R 15$ cell. Inactivation of $I_{R}$ is maximal at $+20 \mathrm{mV}$ and declines as the pulse potential is made more depolarized. Similar results were obtained from 4 R 15 cells. The bell-shaped relationship between pulse potential and $I_{R}$ inactivation is characteristic of cellular processes that are caused by $\mathrm{Ca}^{2+}$ influx, such as synaptic release of neurotransmitter (Katz and Miledi, 1967), activation of $\mathrm{I}_{\mathrm{K}(\mathrm{Ca})}$ (Meech and Standen, 1975), and inactivation of voltage-gated $\mathrm{Ca}^{2+}$ current (Eckert and Tillotson, 1981). 
A
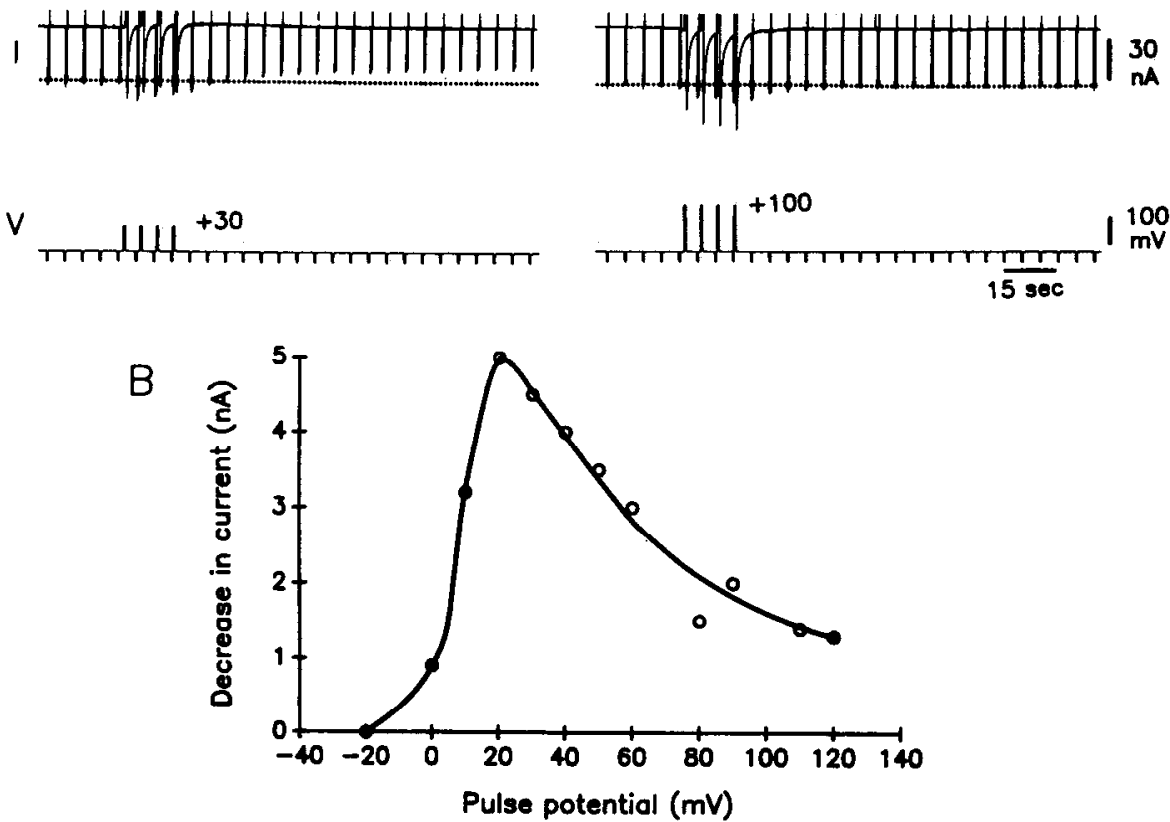

Figure 6. Effect of pulse potential on inactivation of $\mathrm{I}_{\mathrm{R}} . A$, A burst of 400 msec depolarizing pulses to +30 causes a large inactivation of $I_{R}$, while a burst of pulses to $+100 \mathrm{mV}$ causes little change in $I_{R} \cdot I_{R}$ was elicited by repeated $400 \mathrm{msec}$ pulses to $-105 \mathrm{mV}$ from a holding potential of $-75 \mathrm{mV}$. Broken line signifies the basal level of $I_{R}$ before the bursts. $B$, Relationship between pulse potential of the simulated burst and decrease in membrane current measured between -75 and $-115 \mathrm{mV}$. Membrane current was measured $15 \mathrm{sec}$ before and $90 \mathrm{sec}$ after the burst, as in Figure 3.

$\mathrm{Ca}^{2+}$ influx can also be prevented by completely removing $\mathrm{Ca}^{2+}$ from the bathing medium or adding divalent cation blockers of $\mathrm{Ca}^{2+}$ channels, such as $\mathrm{Co}^{2+}$ or $\mathrm{Mn}^{2+}$. Unfortunately, concentrations of $\mathrm{Co}^{2+}$ or $\mathrm{Mn}^{2+}$ sufficient to completely block voltage-gated $\mathrm{Ca}^{2+}$ current (i.e., $10-20 \mathrm{~mm}$ ) also block $\mathrm{I}_{\mathrm{K}}$ (unpublished observations). However, we found that saline containing no added $\mathrm{Ca}^{2+}$ and $3 \mathrm{~mm} \mathrm{Mn}{ }^{2+}$ greatly reduces the voltage-gated inward current activated at membrane potentials more positive than $-75 \mathrm{mV}$ without substantially reducing $I_{R}$. The effect of normal and $\mathrm{Ca}^{2+}$-free $3 \mathrm{mM} \mathrm{Mn}^{2+}$ saline on $I_{R}$ inactivation is shown in Figure 7. In this cell, and in 3 other R 15 cells, a single burst in $\mathrm{Ca}^{2+}$-free saline elicited no detectable inactivation of $I_{R}$.

$\mathrm{Ca}^{2+}$-dependent processes can also be blocked by loading cells with a $\mathrm{Ca}^{2+}$ chelator, such as EGTA. Figure 8 shows the effect of a burst on the I-V curve before (Fig. $8 A$ ) and after (Fig. $8 B$ ) iontophoretic injection of EGTA into cell R15. EGTA injection nearly completely blocks the inactivation of $I_{R}$ caused by the burst. The injection also results in an $18 \%$ increase in the basal $I_{R}$, suggesting that EGTA removes some pre-existing inactiva- tion of $\mathrm{I}_{\mathrm{R}}$ by lowering the resting $\mathrm{Ca}^{2+}$ concentration. In addition, EGTA injection eliminates the effect of the burst on the voltagegated $\mathrm{Ca}^{2+}$ current activated positive to $-75 \mathrm{mV}$, presumably by preventing $\mathrm{Ca}^{2+}$-dependent inactivation of the $\mathrm{Ca}^{2+}$ current. In each of 3 other R 15 cells, EGTA injection reduced the effect of the burst on $I_{R}$ by at least $75 \%$.

\section{Discussion}

The results presented in this paper demonstrate that $I_{R}$, an inwardly rectifying $\mathrm{K}^{+}$current in cell $\mathrm{R} 15$, is inactivated by the influx and accumulation of $\mathrm{Ca}^{2+}$. Moreover, the inactivation of $I_{R}$ is generated by the physiological influx of $\mathrm{Ca}^{2+}$ during spontaneous bursting pacemaker activity. Hence, inactivation of $I_{R}$ is another process that can be added to the extensive list of cellular events regulated by physiological changes in intracellular $\mathrm{Ca}^{2+}$

The $\mathrm{Ca}^{2+}$-dependent regulation of a variety of $\mathrm{K}^{+}$currents is well known. There are at least 2 distinct $\mathrm{Ca}^{2+}$-activated $\mathrm{K}^{+}$currents, studied in several preparations including molluscan neu-
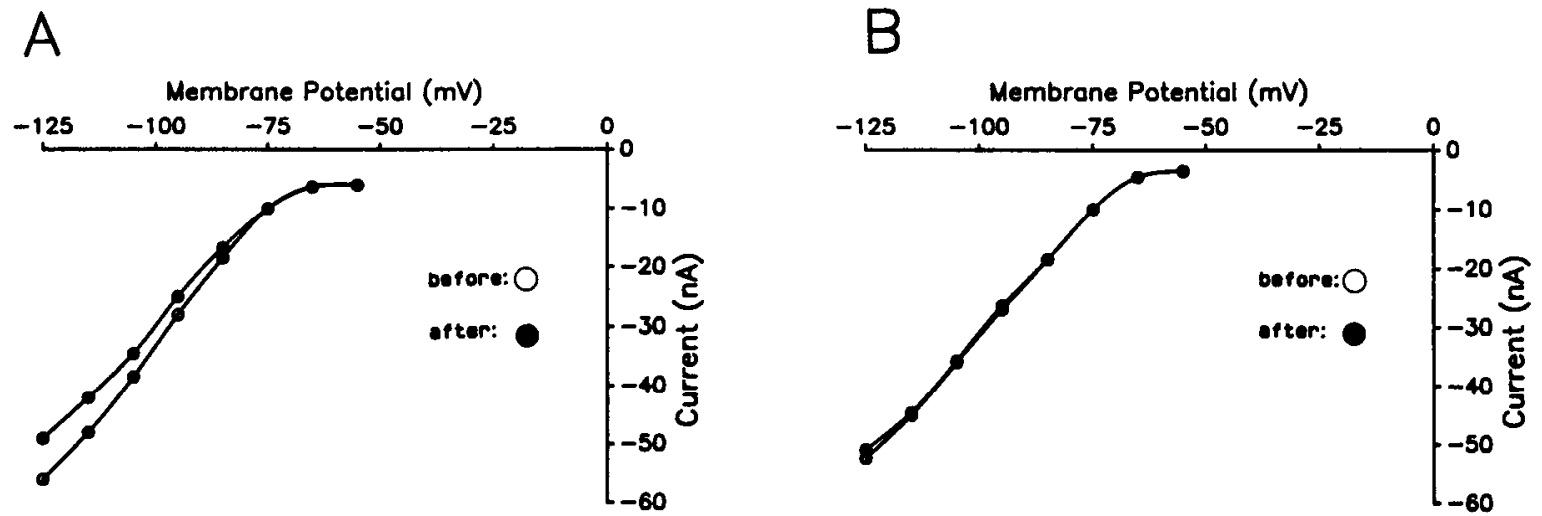

Figure 7. Inactivation of $\mathrm{I}_{\mathrm{R}}$ is blocked in $\mathrm{Ca}^{2+}$-free saline. $A$, Effect of the burst on the I-V curve in normal saline. $B$, Effect of the burst on the $\mathrm{I}-\mathrm{V}$ curve in saline containing no added $\mathrm{Ca}^{2+}$ and $3 \mathrm{mM} \mathrm{Mn}{ }^{2+}$. I-V curves were obtained 15 sec before and 90 sec after the burst, as in Figure 3 . 

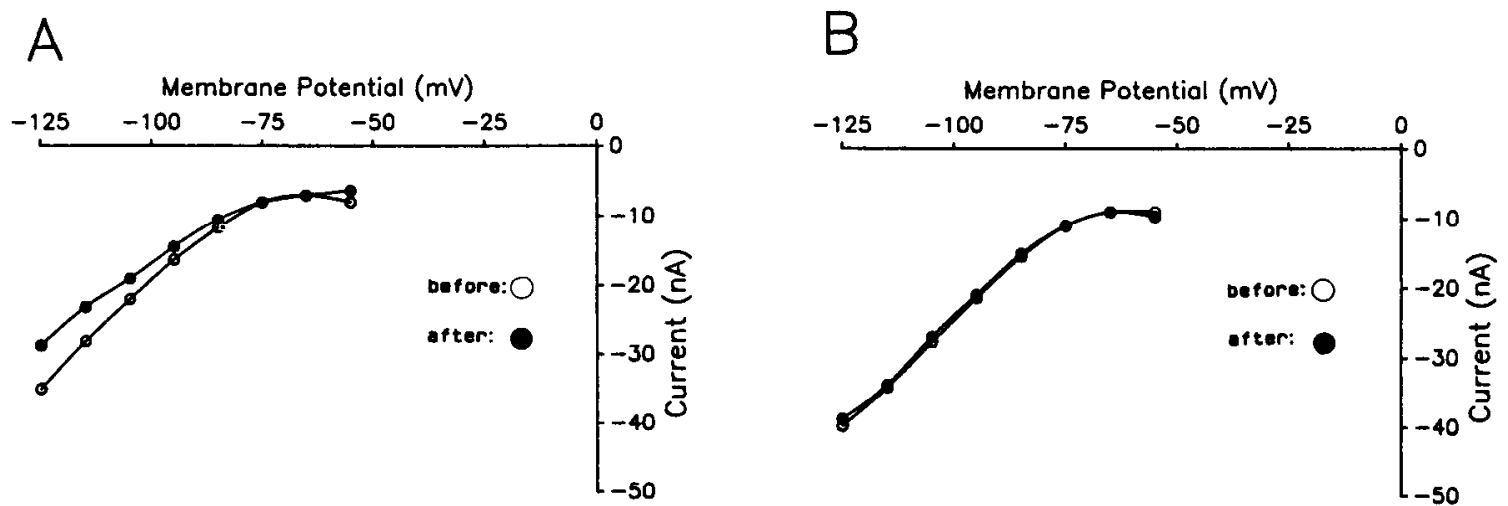

Figure 8. Inactivation of $\mathrm{I}_{\mathrm{R}}$ is blocked by EGTA injection. $A$, Effect of the burst on the $\mathrm{I}-\mathrm{V}$ curve in normal saline. $B$, Effect of the burst 20 min after iontophoretic injection of EGTA into cell R15. I-V curves were obtained $15 \mathrm{sec}$ before and $90 \mathrm{sec}$ after the burst, as in Figure 3.

rons, that can be distinguished on the basis of their $\mathrm{Ca}^{2+}$ sensitivity, voltage-dependence, single-channel conductance, and sensitivity to block by pharmacological agents (Latorre et al., 1984; Blatz and Magleby, 1986; Jones and Adams, 1987). In addition, $\mathrm{Ca}^{2+}$ activates a fast, transient $\mathrm{K}^{+}$current in Drosophila (Salkoff, 1983), similar to $I_{A}$ of molluscan neurons (see D. J. Adams et al., 1980). The $\mathrm{K}^{+}$current studied in this report is distinct from all of these $\mathrm{K}^{+}$currents in 2 important respects: (1) $I_{R}$ activates upon hyperpolarization rather than depolarization, and (2) $I_{R}$ is inactivated rather than activated by internal $\mathrm{Ca}^{2+}$. $\mathrm{Ca}^{2+}$-dependent inactivation of $\mathrm{K}^{+}$current does not appear to be unique to Aplysia neurons, however; there have been recent reports of $\mathrm{Ca}^{2+}$ inactivating $\mathrm{K}^{+}$currents in human $\mathrm{T}$ lymphocytes (Bregestovski et al., 1986), and in Limulus (Chinn and Lisman, 1984) and Hermissenda (Alkon et al., 1984) photoreceptors. In addition, high concentrations of internal $\mathrm{Ca}^{2+}(1 \mathrm{mM}$ and above) block conduction of $\mathrm{K}^{+}$through the pore of certain $\mathrm{Ca}^{2+}$-activated $\mathrm{K}^{+}$channels (Vergara and Latorre, 1983).

The $\mathrm{Ca}^{2+}$-dependent inactivation of $I_{R}$ is remarkably longlasting. The effect of a single burst of spikes causes an inactivation of $I_{R}$ that persists for over $10 \mathrm{~min}$, much longer than the duration of the intracellular $\mathrm{Ca}^{2+}$ transient generated by a burst of spikes in R15 (i.e., 15-30 sec; Gorman and Thomas, 1978). Thus, the recovery of the intracellular $\mathrm{Ca}^{2+}$ transient is not ratelimiting for the recovery of $I_{R}$ from inactivation, suggesting that $\mathrm{Ca}^{2+}$ does not regulate $\mathrm{I}_{\mathrm{R}}$ directly, but through an intermediate process. In addition, the inactivation of $I_{R}$ lasts much longer than the average period of bursts in R15 (i.e., 15-30 sec). Hence, the $\mathrm{Ca}^{2+}$ that enters during bursts of action potentials appears to set the steady-state level of $I_{R}$ over long time periods, rather than to cause oscillations of the current from one burst to the next. In contrast, the subthreshold $\mathrm{Ca}^{2+}$ current of $A$ plysia bursting neurons does oscillate during the bursting rhythm, in part because of $\mathrm{Ca}^{2+}$-dependent inactivation (Kramer and Zucker, $1985 b)$. It is interesting to note that $\mathrm{Ca}^{2+}$-dependent inactivation of $I_{R}$ is an intrinsic cellular mechanism that operates over a time course of many minutes. Such a long-term action is often thought to be in the realm of processes regulated by extracellular neuromodulatory substances.

\section{Functional significance}

What are the functional implications of $I_{R}$ and of its $\mathrm{Ca}^{2+}$-dependent inactivation in cell $R 15$ ? The activation of $I_{R}$ is steeply voltage-dependent, gating strongly with hyperpolarization negative to $-75 \mathrm{mV}$, such that very little $I_{R}$ is present within the voltage range that $R 15$ traverses during normal bursting pacemaker activity (i.e., -55 to $-35 \mathrm{mV}$, excluding action potentials). For example, in an active cell the amplitude of $I_{R}$ is less than $1 \mathrm{nA}$ at $-55 \mathrm{mV}$, if the current is measured immediately after the cell is voltage-clamped (unpublished observations). Hence, in the absence of neuromodulators, it is unlikely that $I_{R}$ plays a major role either in generating the bursting activity or as a background current in setting the amplitude of the membrane potential oscillation.

The importance of $I_{R}$ is greater when $R 15$ is exposed to certain modulatory neurotransmitters. $I_{R}$ is enhanced by 5-HT (Benson and Levitan, 1983) and ELH (Levitan et al., 1987), both of which induce an augmentation of both the depolarized bursting phase and the hyperpolarized interburst phase of pacemaker activity in R15. In the presence of 5-HT or ELH, $I_{k}$ appears to be large enough to provide a considerable background current, sufficient to drive the membrane potential toward the $\mathrm{K}^{+}$equilibrium potential during the interburst hyperpolarization. The voltage-dependent activation of $I_{R}$ may act to amplify the interburst hyperpolarization, as well as other hyperpolarizing stimuli (e.g., inhibitory synaptic potentials) by causing a regenerative hyperpolarization. Indeed, recent results have demonstrated that intracellular injection of hyperpolarizing current pulses causes a long-lasting inhibition of R15 in the presence of an enhanced $I_{R}$ (Levitan and Levitan, 1988). We suggest that $\mathrm{Ca}^{2+}$ influx during bursting pacemaker activity limits the effects of modulators such as 5-HT and ELH on $\mathrm{I}_{\mathrm{R}}$ by causing $\mathrm{Ca}^{2+}$ dependent inactivation of $I_{R}$. Hence, the duration and amplitude of modulatory effects on $\mathrm{I}_{\mathrm{R}}$ may be lessened by $\mathrm{Ca}^{2 \dagger}$-dependent inactivation (see Kramer et al., 1988).

Conversely, if $\mathrm{Ca}^{2+}$ influx into cell $\mathrm{R} 15$ is reduced, then the effects of transmitters that increase $I_{R}$ may be accentuated. There is a synaptic input ("input III") onto R15 that both increases $I_{R}$ and causes a large decrease in the subthreshold $\mathrm{Ca}^{2+}$ current (W. B. Adams et al., 1980). Activation of input III causes an extremely long-lasting (e.g., $45 \mathrm{~min}$ ) inhibition of bursting activity in R15 (Parnas and Strumwasser, 1974). There is the intriguing possibility that the long-term inhibition is in part duc to a decrease in $\mathrm{Ca}^{2+}$-dependent inactivation of $\mathrm{I}_{\mathrm{R}}$. This possibility needs to be tested in further experiments.

The long time course and the apparent delay in the onset of 
$\mathrm{Ca}^{2+}$-dependent inactivation suggest that a complex biochemical mechanism may be involved in the mechanism of $\mathrm{Ca}^{2+}$ action on $I_{R}$. Since $I_{R}$ is enhanced by cAMP, one possibility is that $\mathrm{Ca}^{2+}$ exerts its effect on $I_{R}$ by interacting with the cAMP metabolic cascade. The following paper (Kramer et al., 1988) addresses this issue.

\section{References}

Adams, D. J., S. J. Smith, and S. H. Thompson (1980) Ionic currents in molluscan somata. Annu. Rev. Neurosci. 3: 141-167.

Adams, W. B., and I. B. Levitan (1985) Voltage and ion dependences of the slow currents which mediate bursting in Aplysia neurone R15. J. Physiol. (Lond.) 360: 69-93.

Adams, W. B., I. Parnas, and I. B. Levitan (1980) Mechanism of longlasting synaptic inhibition in Aplysia neuron R15. J. Neurophysiol. 44: 1148-1160.

Alkon, D. L., J. J. Shoukimas, and E. Heldman (1984) Calciummediated decrease of a voltage-dependent potassium current. Biophys. J. 40:245-250.

Barish, M. E. (1983) A transient calcium-dependent chloride current in the immature Xenopus oocyte. J. Physiol. (Lond.) 342: 309-325.

Benson, J. A., and I. B. Levitan (1983) Serotonin increases an anomalously rectifying $\mathrm{K}^{+}$current in the Aplysia neuron R15. Proc. Natl. Acad. Sci. USA 80: 3522-3525.

Blatz, A. L. and K. L. Magelby (1986) Single apamin-blocked Caactivated $\mathrm{K}^{+}$channels of small conductance in cultured rat skeletal muscle. Nature 323: 718-720.

Bregestovski, P., A. Redkozubov, and A. Alexeev (1986) Elevation of intracellular calcium reduces voltage-dependent potassium conductance in human T cells. Nature 319: 776-778.

Chesnoy-Marchais, D. (1983) Characterization of a chloride conductance activated by hyperpolarization in Aplysia neurones. J. Physiol. (Lond.) 342: 277-308.

Chinn, K., and J. Lisman (1984) Calcium mediates the light-induced decrease in maintained $\mathrm{K}^{+}$current in Limulus photoreceptors. J. Gen. Physiol. 84: 447-462.

Colquhoun, D., E. Neher, H. Reuter, and C. F. Stevens (1981) Inward current channels activated by intracellular $\mathrm{Ca}$ in cultured cardiac cells. Nature 294: 752-754.

Coyer, P. E., J. H. Halsey, Jr., and E. R. Strong (1983) Reversible changes in the intracellular potassium ion activities and membrane potentials of Aplysia L2-L6 neurones in response to normoxia and hypoxia. J. Exp. Biol. 102: 79-92.

Drummond, A. H., J. A. Benson, and I. B. Levitan (1980) Serotonininduced hyperpolarization of an identified Aplysia neuron is mediated by cyclic AMP. Proc. Natl. Acad. Sci. USA 77: 5013-5017.

Eckert, R., and J. E. Chad (1984) Inactivation of Ca channels. Prog. Biophys. Mol. Biol. 44: 215-267.

Eckert, R., and H. D. Lux (1976) A voltage-sensitive persistent calcium conductance in neuronal somata of Helix. J. Physiol. (Lond.) 254: 129-151.

Eckert, R., and D. Tillotson (1981) Calcium-mediated inactivation of the calcium conductance in caesium-loaded giant neurones of Aplysia. J. Physiol. (Lond.) 314: 265-280.

Gorman, A. L. F., and A. Hermann (1979) Internal effects of divalent cations on potassium permeability in molluscan neurones. J. Physiol. (Lond.) 296: 393-410.

Gorman, A. L. F., and M. V. Thomas (1978) Changes in the intracellular concentration of free calcium ions in a pace-maker neurone, measured with the metallochromic indicator dye arsenazo III. J. Physiol. (Lond.) 275: 357-376.

Gorman, A. L. F., A. Hermann, and M. V. Thomas (1982) Ionic requirements for membrane oscillations and their dependence on the calcjum concentration in a molluscan pace-maker neurone. J. Physiol. (Lond.) 327: 185-217.

Hagiwara, S., and L. Byerly (1981) Calcium channel. Annu. Rev. Neurosci. 4: 69-125.

Hagiwara; S., and K. Takahashi (1974) The anomalous rectification and cation selectivity of the membrane of the starfish egg cell. J. Membr. Biol. 18: 61-80.

Hagiwara, S., S. Miyazaki, W. Moody, and J. Patlak (1978) Blocking effects of barium and hydrogen ions on the potassium current during anomalous rectification in the starfish egg. J. Physiol. (Lond.) 279: 167-185.

Jones, S. W., and P. R. Adams (1987) The M-current and other potassium currents of vertebrate neurons. In Neuromodulation, L. K. Kaczmarek and I. B. Levitan, eds., pp. 159-186, Oxford U. P., New York.

Katz, B., and R. Miledi (1967) A study of synaptic transmission in the absence of nerve impulses. J. Physiol. (Lond.) 192: 407-436.

Kramer, R. H., and I. B. Levitan (1986) Calcium influx modulates a cyclic AMP-regulated ionic conductance in Aplysia bursting pacemaker neurons. Soc. Neurosci. Abstr. 12: 1001.

Kramer, R. H., and R. S. Zucker (1985a) Calcium-dependent inward current in Aplysia bursting pace-maker neurones. J. Physiol. (Lond.) 362: 107-130.

Kramer, R. H., and R. S. Zucker (1985b) Calcium-induced inactivation of calcium current causes the interburst hyperpolarization of Aplysia bursting pacemaker neurones. J. Physiol. (Lond.) 362: 131160.

Kramer, R. H., E. S. Levitan, M. P. Wilson, and I. B. Levitan (1988) Mechanism of calcium-dependent inactivation of a potassium current in Aplysia neuron R 15: Interaction between calcium and cyclic AMP. J. Neurosci. 8: 1804-1813.

Latorre, R., R. Coronado, and C. Vergara (1984) $\mathrm{K}^{+}$channels gated by voltage and ions. Annu. Rev. Physiol. 46: 485-495.

Levitan, E. S., and I. B. Levitan (1988) Serotonin acting via cyclic AMP enhances both the hyperpolarizing and depolarizing phases of bursting paccmaker activity in the Aplysia neuron R15. J. Neurosci. 8: $1152-1161$.

Levitan, E. S., R. H. Kramer, and I. B. Levitan (1987) Augmentation of bursting pacemaker activity in Aplysia neuron R 15 by egg-laying hormone is mediated by a cyclic AMP-dependent increase in $\mathrm{Ca}^{2+}$ and $\mathrm{K}^{+}$currents. Proc. Natl. Acad. Sci. USA 84: 6307-6311.

Levitan, I. B., and W. B. Adams (1981) Cyclic AMP modulation of a specific ion channel in an identified nerve cell: Possible role for protein phosphorylation. Adv. Cyclic Nucleotide Res. 14: 647-653.

Levitan, I. B., and A. H. Drummond (1980) Neuronal serotonin receptors and cyclic AMP: Biochemical, pharmacological and electrophysiological analysis. In Neurotransmitters and their Receptors, U. Z. Littauer, Y. Dudai, I. Silman, V. I. Teichberg, and Z. Vogel, eds., pp. 163-176, Wiley, Chichester.

Lotshaw, D. P., E. S. Levitan, and I. B. Levitan (1986) Fine tuning of neuronal electrical activity: Modulation of several ion channels by intracellular messengers in a single identified nerve cell. J. Exp. Biol. 124: 307-322.

Maruyama, Y., and O. H. Petersen (1982) Single-channel currents in isolated patches of plasma membrane from basal surface of pancreatic acini. Nature 299: 159-161.

Meech, R. W. (1978) Calcium-dependent potassium activation in nervous tissues. Annu. Rev. Biophys. Bioeng. 7: 1-18.

Meech, R. W. (1979) Membrane potential oscillations in molluscan "burster" neurones. J. Exp. Biol. 81: 93-112.

Meech, R. W., and N. B. Standen (1975) Potassium activation in Helix aspersa neurones under voltage clamp; a component mediated by calcium influx. J. Physiol. (Lond.) 249: 211-239.

Parnas, I., and F. Strumwasser (1974) Mechanisms of long-lasting inhibition of a bursting pacemaker neuron. J. Neurophysiol. 37:609620.

Sakmann, B., and G. Trube (1984) Conductance properties of single inwardly rectifying potassium channels in ventricular cells from guineapig heart. J. Physiol. (Lond.) 347: 641-657.

Salkoff, L. (1983) Drosophila mutants reveal two components of fast outward current. Nature 302: 249-251.

Standen, N. B., and P. R. Stanfield (1978) A potential- and timedependent blockade of inward rectification in frog skeletal muscle fibres by barium and strontium ions. J. Physiol. (Lond.) 280: 169191.

Standen, N. B., and P. R. Stanfield (1980) Rubidium block and rubidium permeability of the inward rectifier of frog skeletal muscle fibres. J. Physiol. (Lond.) 304: 415-435.

Vergara, C., and R. Latorre (1983) Kinetics of Ca-activated K-channels from rabbit muscle incorporated into planar bilayers: Evidence for a $\mathrm{Ca}^{2+}$ and $\mathrm{Ba}^{2+}$ blockage. J. Gen. Physiol. 82: 543-568.

Yellen, G. (1982) $\mathrm{Ca}^{2+}$-activated nonselective cation channels in neuroblastoma. Nature 296: 357-359. 